\title{
Natural Convective Effects on MHD Boundary Layer Nanofluid Flow over an Exponentially Accelerating Vertical Plate
}

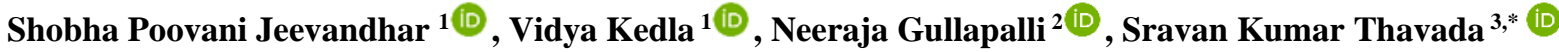 \\ 1 Department of Mathematics, Shri Dharmasthala Manjunatheshwara College of Engineering \& Technology, Ujire- \\ 574240, Karnataka, India; ssdhegde1@gmail.com (S.P.J.); vidyasomayaji@gmail.com (V.K.); \\ 2 Department of Mathematics, M S Ramaiah Institute of Technology, Bangalore-560 054, Karnataka, India.; \\ gneerajamaths@gmail.com (N.G.); \\ 3 Department of Mathematics, SoAS, REVA University, Bangalore-560 064, Karnataka, India; \\ thavadasravankumar@gmail.com (S.K.T.); \\ * Correspondence: thavadasravankumar@gmail.com (S.R.T.);
}

Scopus Author ID 56872884700

Received: 20.01.2021; Revised: 15.02.2021; Accepted: 20.02.2021; Published: 01.03.2021

Abstract: The problem of unsteady natural convective nanofluid flow along with an exponentially accelerating vertical plate under the influence of transverse magnetic field is discussed in two important cases when the magnetic lines of force are fixed relative to the fluid or the moving plate. The governing equations are transformed into dimensionless form and tackled with the usual time-frequency Laplace transform technique. The impacts of various parameters on the heat transfer characteristics and nanofluid flow transport with thermal radiation, heat generation/absorption, and nanoparticle volume concentration have been studied through graphs.

Keywords: MHD; nanofluids; natural convection; thermal radiation; accelerating plate.

(c) 2021 by the authors. This article is an open-access article distributed under the terms and conditions of the Creative Commons Attribution (CC BY) license (https://creativecommons.org/licenses/by/4.0/).

\section{Introduction}

Convective flow and heat transfer are important elements in several engineering processes. Numerous studies were performed to enhance common heat transfer fluids' thermal properties, namely water, oil, and ethylene glycol. The technique of suspending solid nanoparticles into these fluids termed 'nanofluids' was coined by Choi [1]. The investigations on nanofluids are widely executing because the thermal conductivity of nanofluids is greater than traditional fluids. Eastman et al. [2] highlighted that by adding 5 vol. \% $\mathrm{CuO}$ nanoparticles into the base fluid water, about $60 \%$ enhancement in fluid thermal conductivity was recorded. It was also shown by Choi et al. [3] that the thermal conductivity of oil-based nanofluids improved twofold when a small amount of nanotubes (less than 1 vol. \%) was added. Meanwhile, Akmal et al. [4] studied the temperature effect on nanofluids' thermal conductivity and revealed that the thermal conductivity increased dramatically with temperature. Further reading can be done with the review articles from Kumar et al. [5], Das and Choi [6], and Kumar [7]. Many investigations were conducted for decades to unveil the properties of nanofluid flow and its applications. For example, Kumar et al. [8] addressed the effects of Brownian motion and thermophoresis on the natural convection flow of nanofluid past a 
vertical plate. They concluded that the reduced local Nusselt number was decreased with the rise of buoyancy-ratio, Brownian motion, and thermophoresis parameters. Shah et al. [9] analyzed the convective heat transfer of water-based nanofluids past a stretching sheet by using the Keller box method. It was concluded that Ag-water nanofluid has a higher heat transfer rate than the $\mathrm{Cu}$-water nanofluid. Tiwari [10] applied the finite element method to examine the temperature-dependent heat source/sink on nanofluid mixed convection flow. They identified that $\mathrm{Ag}$ nanoparticles have the best performance in cooling while $\mathrm{TiO}_{2}$ nanoparticles have the lowest cooling performance. Mahdy and El-Shehabey [11] considered the thermal conductivity and dynamic viscosity uncertainties on the problem of non-linear flow and heat transfer past a horizontal stretching surface with nanofluids. Also, Mahdy [12] investigated the unsteady mixed convection flow of nanofluids past a linearly stretching vertical surface with thermal conductivity and dynamic viscosity uncertainties. He found that the use of nanofluids enhanced the thermal boundary layer and reduced the momentum boundary layer. Rajesh et al. [13] employed the Crank-Nicolson implicit finite-difference method to investigate the unsteady natural convective nanofluid flow over a semi-infinite vertical plate with variable surface temperature. Kumaresan et al. [14] used the optimal collocation method (OCM) to study the nanofluid boundary layer flow over a moving semi-infinite porous plate. Cao et al. [15] applied the finite difference method with L1-algorithm to examine the unsteady Maxwell viscoelastic nanofluid flow over a moving plate.

Mohanthesh et al. [16] investigated the MHD three-dimensional flow of viscous nanofluid over a non-linear bidirectional surface. Hamad et al. [17] studied the magnetic field effect on free convective nanofluid flow past a semi-infinite vertical flat plate. Chamkha and Khan et al. [18] presented the MHD steady natural convection flow of nanofluids over a permeable vertical plate. Meanwhile, Ibrahim and Gadisa [19] addressed the MHD free convective nanofluid flow past a stretching surface and concluded that the heat transfer rate reduced in the $\mathrm{Cu}$-water nanofluid the nanoparticle volume fraction increased. Turkyilmazoglu and Pop [20] analyzed the transient free convection flow past a vertical flat plate utilizing nanofluids with radiation effect. The isothermal and isoflux boundary conditions were considered in this case, and similarity variable analysis was used to tackle the resulting equations. Similarly, Turkyilmazoglu [21] investigated the transient natural convection flow along with a moving vertical plate in nanofluids with isothermal and isoflux boundary conditions. His study revealed that the radiation effect enhances the physical properties of nanofluid. Sheikholeslami et al. [22] examined the convective transport of MHD CuO-water nanofluid in an enclosure using the lattice Boltzmann method with the Koo-Kleinstreuer-Li (KKL) correlation. In addition to that, the problem of MHD unsteady nanofluid flow and heat transfer with thermal radiation was examined by Ahmed et al. [23]. Naveed Khan et al. [24] investigated the effects of heat generation on the natural convection flow of a nanofluid over a vertical plate and concluded that the increased nanoparticle volume concentration increased the heat transfer rate and nanofluid temperature. Pedram and Ehsan [25] presented the case of nanofluid flow past a stretching/shrinking sheet in a porous medium by using four different types of nanoparticles. It was proved that the nanofluid flow was significantly affected by the effective electrical conductivity when the magnetic field is applied. Nadjia and Nadji [26] utilized the homotopic analysis to elucidate the inclined magnetic field's effects and non-linear thermal radiation on the melting heat transfer in stagnation point flow over a stretching sheet. Ali et al. [27] studied the transient MHD flow of water-based nanofluids along with a vertical plate in a porous medium with the time-dependent plate velocity, temperature, and 
concentration. They computed the results by fixing the Prandtl number at $\operatorname{Pr}=0.71$ (air), which is not valid for water-based nanofluids. Their results are unrealistic. Recently, Kataria and Mittal [28] studied the mass transfer effects on the MHD gravity-driven convective flow of nanofluids over an oscillating vertical plate using the Laplace transform method, and the results were presented for inappropriate values of Schmidt number.

Nevertheless, in the provided literature, the study of nanofluids' natural convection flow past a moving vertical plate with different magnetic field cases is neglected. What happens to the nanofluid flow characteristics when the magnetic field is fixed relative to the nanofluid or the moving plate? The present study tries to answer this question. In fact, this situation is involved in many engineering applications like MHD accelerators, MHD pumps, MHD generators, plasma physics, material processing, and manufacturing technology [29]. Therefore, the present study deals with the MHD free convection and nanofluid flow past an accelerating plate with uniform temperature when the magnetic lines of force are fixed relative to the fluid or the moving plate in the presence of thermal radiation and heat generation/absorption. Three different types of nanoparticles, namely $\mathrm{Cu}, \mathrm{Ag}$, and $\mathrm{CuO}$ in the base fluid water, are considered, and the exact solutions to the governing equations are obtained using the Laplace transform technique.

\section{Mathematical Formulation}

Consider the unsteady free convective flow and heat transfer of nanofluids past an exponentially accelerating infinite vertical plate with uniform temperature. The $x$-axis is pointing along with the plate in the vertical direction, while the $y$-axis is directed perpendicular to the plate and parallel to the applied transverse magnetic field (Figure 1). Initially, the plate and the surrounding nanofluid are assumed to be at the same temperature in a static condition in the entire flow region $y \geq 0$. At the time $t>0$, the plate begins to move in its own plane with the velocity $u_{0} f(t)$ in the vertical direction, and the temperature of the plate is suddenly increased to $T_{w}$. It is assumed that a uniform magnetic field $B_{0}$ is applied perpendicular to the plate, and the heat due to viscous and Joule dissipation is neglected. The radiative heat flux, $q_{r}$ normal to the plate, is also considered significant compared to that of the plate direction. Three types of nanofluids with the base fluid as water containing the nanoparticles $\mathrm{Cu}, \mathrm{Ag}$, and $\mathrm{CuO}$ are considered. Then the governing equations of natural convective flow in the presence of heat generation/absorption are obtained as below:

Table 1. Thermophysical properties of nanoparticles and water [34].

\begin{tabular}{c|c|c|c|c} 
Physical Properties & Water/ Base fluid & Cu (Copper) & Ag (Silver) & CuO (Copper Oxide) \\
\hline Density $\left(\mathrm{kg} / \mathrm{m}^{3}\right)$ & 997.1 & 8933 & 10500 & 6320 \\
\hline$c_{p}(\mathrm{~J} / \mathrm{kg} . \mathrm{K})$ & 4179 & 385 & 235 & 531.8 \\
\hline$\kappa(\mathrm{W} / \mathrm{m} . \mathrm{K})$ & 0.613 & 401 & 429 & 76.5 \\
\hline$\beta \times 10^{5}\left(\mathrm{~K}^{-1}\right)$ & 21 & 1.67 & 1.89 & 1.80 \\
\hline$\sigma(\mathrm{S} / \mathrm{m})$ & 0.05 & $59.6 \times 10^{6}$ & $63.0 \times 10^{6}$ & $2.7 \times 10^{-8}$
\end{tabular}




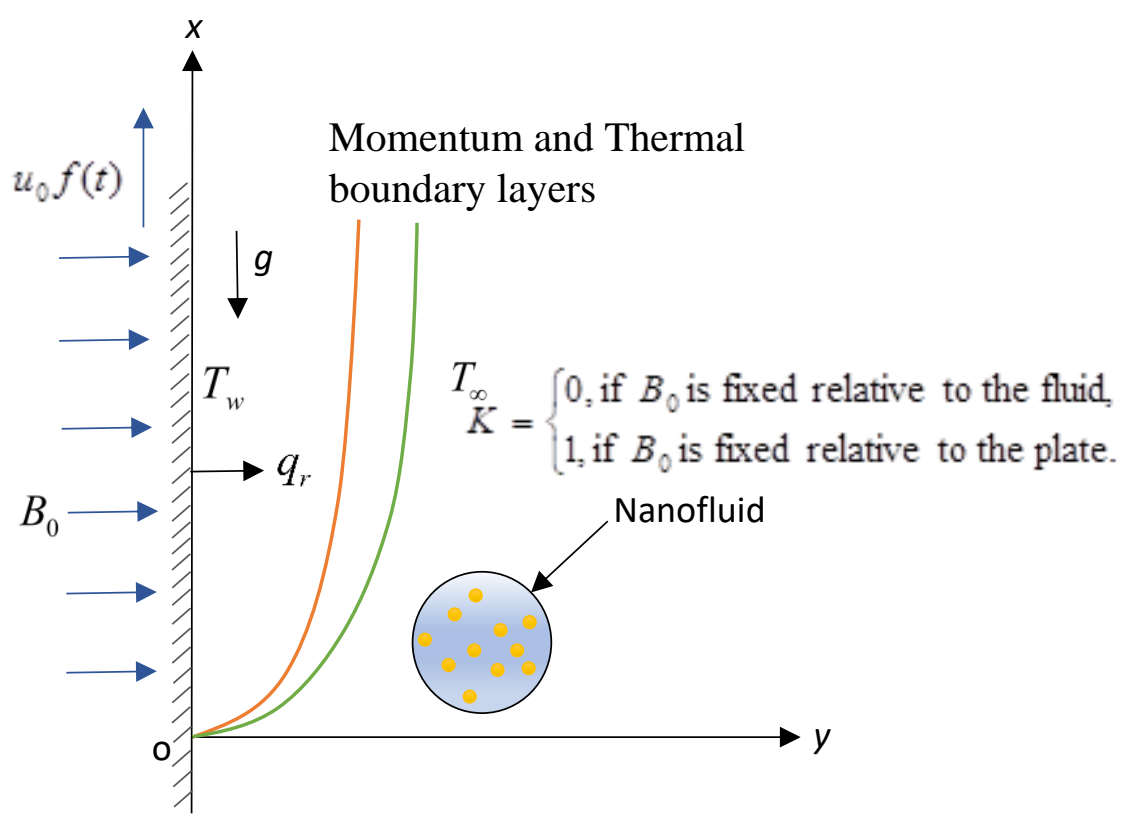

Figure 1. Schematic nanofluid flow model.

The equations of the flow problem are defined as:

$\rho_{n f} \frac{\partial u}{\partial t}=\mu_{n f} \frac{\partial^{2} u}{\partial y^{2}}+g(\rho \beta)_{n f}\left(T-T_{\infty}\right)-\sigma_{n f} B_{0}^{2} u$

$\left(\rho c_{p}\right)_{n f} \frac{\partial T}{\partial t}=k_{n f} \frac{\partial^{2} T}{\partial y^{2}}-\frac{\partial q_{r}}{\partial y}-Q_{0}\left(T-T_{\infty}\right)$.

When the magnetic lines of force are fixed relative to the plate, the momentum Eq. (1), can be written as (see [30 -32]),

$\rho_{n f} \frac{\partial u}{\partial t}=\mu_{n f} \frac{\partial^{2} u}{\partial y^{2}}+g(\rho \beta)_{n f}\left(T-T_{\infty}\right)-\sigma_{n f} B_{0}^{2}\left[u-u_{0} f(t)\right]$.

Combining equations (1) and (3) gives

$\rho_{n f} \frac{\partial u}{\partial t}=\mu_{n f} \frac{\partial^{2} u}{\partial y^{2}}+g(\rho \beta)_{n f}\left(T-T_{\infty}\right)-\sigma_{n f} B_{0}^{2}\left[u-K u_{0} f(t)\right]$,

where $K=\left\{\begin{array}{l}0, \text { if } B_{0} \text { is fixed relative to the fluid, } \\ 1, \text { if } B_{0} \text { is fixed relative to the plate. }\end{array}\right.$

The relevant initial and boundary conditions are

$t \leq 0: u=0, T=T_{\infty} \quad$ for all $\quad y \geq 0$,
$t>0:\left\{\begin{array}{lll}u=u_{0} f(t), T=T_{w} & \text { at } & y=0, \\ u \rightarrow 0, T \rightarrow T_{\infty} & \text { as } & y \rightarrow \infty\end{array}\right\}$

For an exponentially accelerating plate, $f(t)=\exp (a t)$, where $a$ is the dimensional accelerating parameter, $u$ is velocity component along the $x$-direction, $Q_{0}$ is heat generation/absorption, $T$ is nanofluid temperature, $g$ is the acceleration due to gravity. In addition, $\mu_{n f}$ is nanofluid dynamic viscosity, $\beta_{n f}$ is nanofluid thermal expansion coefficient, $\rho_{n f}$ is nanofluid density, $\sigma_{n f}$ is nanofluid electrical conductivity, $k_{n f}$ is nanofluid thermal conductivity, and $\left(\rho c_{p}\right)_{n f}$ is nanofluid heat capacitance which is given by 


$$
\left.\begin{array}{l}
\mu_{n f}=\frac{\mu_{f}}{(1-\phi)^{2.5}}, \rho_{n f}=(1-\phi) \rho_{f}+\phi \rho_{s},\left(\rho c_{p}\right)_{n f}=(1-\phi)\left(\rho c_{p}\right)_{f}+\phi\left(\rho c_{p}\right)_{s}, \\
(\rho \beta)_{n f}=(1-\phi)(\rho \beta)_{f}+\phi(\rho \beta)_{s}, \sigma_{n f}=\sigma_{f}\left[1+\frac{3(\sigma-1) \phi}{(\sigma+2)-(\sigma-1) \phi}\right], \sigma=\frac{\sigma_{s}}{\sigma_{f}}
\end{array}\right\}
$$

The nanofluid effective thermal conductivity given by Hamilton and Crosser's model followed by Kakac and Pramuanjaroenkij [5] is

$$
k_{n f}=k_{f}\left[\frac{k_{s}+2 k_{f}-2 \phi\left(k_{f}-k_{s}\right)}{k_{s}+2 k_{f}+\phi\left(k_{f}-k_{s}\right)}\right] \text {, }
$$

where $k_{f}$ is base fluid thermal conductivity and $k_{s}$ is nanoparticle thermal conductivity. Eq. (7) expression is restricted to spherical nanoparticles, where other nanoparticle shapes are not considered. Since the nanofluid is considered to be an optically thick fluid, the Rosseland approximation [33] is adopted to approximate the radiative heat flux $q_{r}$ in Eq. (2). Following the study by Turkyilmazoglu and Pop [20], Eq. (2) can be written as

$$
\frac{\partial T}{\partial t}=\frac{1}{\left(\rho c_{p}\right)_{n f}}\left(k_{n f}+\frac{16 \sigma^{*} T^{3}}{3 k^{*}}\right) \frac{\partial^{2} T}{\partial y^{2}}-Q_{0}\left(T-T_{\infty}\right) \text {. }
$$

Introducing the non-dimensional variables as

$$
\eta=\frac{u_{0} y}{v_{f}}, \tau=\frac{u_{0}^{2} t}{v_{f}}, U=\frac{u}{u_{0}}, \theta=\frac{T-T_{\infty}}{T_{w}-T_{\infty}}, a_{0}=\frac{a v_{f}}{u_{0}^{2}}, Q=\frac{Q_{0} v_{f}}{u_{0}^{2}\left(\rho c_{p}\right)_{f}},
$$

the dimensionless governing equations are obtained as follows:

$$
\begin{aligned}
& \frac{\partial U}{\partial \tau}=a_{1} \frac{\partial^{2} U}{\partial \eta^{2}}+G r a_{2} \theta-M^{2} a_{3}\left[U-\operatorname{Kexp}\left(a_{0} \tau\right)\right], \\
& \frac{\partial \theta}{\partial \tau}=a_{4} \frac{\partial^{2} \theta}{\partial \eta^{2}}-a_{5} Q \theta,
\end{aligned}
$$

where $\eta, \tau, U, \theta, a_{0}$ and $Q$ are the dimensionless coordinate axis perpendicular to the plate, time, fluid velocity along with the plate, fluid temperature, accelerating parameter, and heat generation/absorption parameter, respectively,

$$
\begin{aligned}
& x_{1}=\left[(1-\phi)+\phi\left(\frac{\rho_{s}}{\rho_{f}}\right)\right], x_{2}=\left[(1-\phi)+\phi \frac{(\rho \beta)_{s}}{(\rho \beta)_{f}}\right], x_{3}=\left[(1-\phi)+\phi \frac{\left(\rho c_{p}\right)_{s}}{\left(\rho c_{p}\right)_{f}}\right], \\
& x_{4}=\left[\frac{k_{s}+2 k_{f}-2 \phi\left(k_{f}-k_{s}\right)}{k_{s}+2 k_{f}+\phi\left(k_{f}-k_{s}\right)}\right], x_{5}=\left[1+\frac{3\left(\frac{\sigma_{s}}{\sigma_{f}}-1\right) \phi}{\left(\frac{\sigma_{s}}{\sigma_{f}}+2\right)-\left(\frac{\sigma_{s}}{\sigma_{f}}-1\right)}\right], a_{1}=\frac{1}{(1-\phi)^{2.5} x_{1}}, a_{2}=\frac{x_{2}}{x_{1}}, \\
& a_{3}=\frac{x_{5}}{x_{1}}, a_{4}=\frac{1}{x_{3} \operatorname{Pr}}\left(x_{4}+N r\right), a_{5}=\frac{1}{x_{3}},
\end{aligned}
$$


$M^{2}=\frac{\sigma_{f} B_{0}^{2} v_{f}}{\rho_{f} u_{0}^{2}}$ is magnetic parameter, $N r=\frac{16 \sigma^{*} T_{\infty}^{3}}{3 k_{f} k^{*}}$ is radiation parameter, $\operatorname{Pr}=\frac{\mu_{f} c_{p}}{k_{f}}$ is Prandtl number, and $G r=\frac{g \beta_{f} v_{f}\left(T_{w}-T_{\infty}\right)}{u_{0}^{3}}$ is Grashof number.

The dimensionless initial and boundary conditions are as follows:

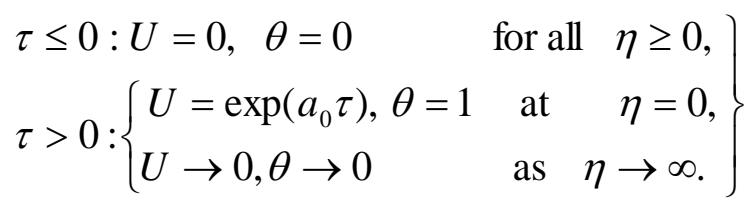

The Eqs. (10) and (11), subject to the boundary conditions (13), are solved by Laplace transform technique. The temperature and velocity solutions are provided as follows:

$$
\begin{aligned}
& \theta(\eta, \tau)=\frac{1}{2}\left[\exp \left(\eta \sqrt{b_{0}}\right) \operatorname{erfc}\left(\frac{\eta}{2 \sqrt{a_{4} t}}+\sqrt{a_{4} b_{0} t}\right)+\exp \left(-\eta \sqrt{b_{0}}\right) \operatorname{erfc}\left(\frac{\eta}{2 \sqrt{a_{4} t}}-\sqrt{a_{4} b_{0} t}\right)\right], \\
& U(\eta, \tau)=\frac{b_{1}}{2 b_{2}}\left[\exp \left(\eta \sqrt{b_{4}}\right) \operatorname{erfc}\left(\frac{\eta}{2 \sqrt{a_{1} t}}+\sqrt{a_{1} b_{4} t}\right)+\exp \left(-\eta \sqrt{b_{4}}\right) \operatorname{erfc}\left(\frac{\eta}{2 \sqrt{a_{1} t}}-\sqrt{a_{1} b_{4} t}\right)\right] \\
& +\frac{\left(1-b_{3}\right) \exp \left(a_{0} t\right)}{2}\left[\exp \left(\eta \sqrt{\mathrm{b}_{5}}\right) \operatorname{erfc}\left(\frac{\eta}{2 \sqrt{a_{1} t}}+\sqrt{a_{1} b_{5} t}\right)+\exp \left(-\eta \sqrt{\mathrm{b}_{5}}\right) \operatorname{erfc}\left(\frac{\eta}{2 \sqrt{a_{1} t}}-\sqrt{a_{1} b_{5} t}\right)\right] \\
& -\frac{b_{1} \exp \left(-b_{2} t\right)}{2 b_{2}}\left[\exp \left(\eta \sqrt{\mathrm{b}_{6}}\right) \operatorname{erfc}\left(\frac{\eta}{2 \sqrt{a_{1} t}}+\sqrt{a_{1} b_{6} t}\right)+\exp \left(-\eta \sqrt{\mathrm{b}_{6}}\right) \operatorname{erfc}\left(\frac{\eta}{2 \sqrt{a_{1} t}}-\sqrt{a_{1} b_{6} t}\right)\right] \\
& +\frac{b_{1} \exp \left(-b_{2} t\right)}{2 b_{2}}\left[\exp \left(\eta \sqrt{\mathrm{b}_{7}}\right) \operatorname{erfc}\left(\frac{\eta}{2 \sqrt{a_{4} t}}+\sqrt{a_{4} b_{7} t}\right)+\exp \left(-\eta \sqrt{\mathrm{b}_{7}}\right) \operatorname{erfc}\left(\frac{\eta}{2 \sqrt{a_{4} t}}-\sqrt{a_{4} b_{7} t}\right)\right] \\
& -\frac{b_{1}}{2 b_{2}}\left[\exp \left(\eta \sqrt{\mathrm{b}_{0}}\right) \operatorname{erfc}\left(\frac{\eta}{2 \sqrt{a_{4} t}}+\sqrt{a_{4} b_{0} t}\right)+\exp \left(-\eta \sqrt{\mathrm{b}_{0}}\right) \operatorname{erfc}\left(\frac{\eta}{2 \sqrt{a_{4} t}}-\sqrt{a_{4} b_{0} t}\right)\right] \\
& +b_{3} \exp \left(-M^{2} a_{3} t\right)\left[\operatorname{erfc}\left(\frac{\eta}{2 \sqrt{a_{1} t}}\right)-1\right]+b_{3} \exp \left(a_{0} t\right),
\end{aligned}
$$

where

$$
\begin{aligned}
& b_{0}=\frac{a_{5} Q}{a_{4}}, b_{1}=\frac{G r a_{2} a_{4}}{a_{1}-a_{4}}, b_{2}=\frac{a_{1} a_{5} Q-M^{2} a_{3} a_{4}}{a_{1}-a_{4}}, b_{3}=\frac{M^{2} a_{3} K}{M^{2} a_{3}+a_{0}}, b_{4}=\frac{M^{2} a_{3}}{a_{1}}, \\
& b_{5}=\frac{M^{2} a_{3}+a_{0}}{a_{1}}, b_{6}=\frac{M^{2} a_{3}-b_{2}}{a_{1}}, b_{7}=\frac{a_{5} Q-b_{2}}{a_{4}} .
\end{aligned}
$$

\subsection{Skin-friction.}

From the velocity field, the non-dimensional form of skin-friction is given as follows:

$$
C_{f}=-\frac{1}{(1-\phi)^{2.5}}\left[\frac{\partial U}{\partial \eta}\right]_{\eta=0} \text {. }
$$

From Eqs. (15) and (16), the skin-friction equation can be derived as follows: 


$$
\begin{aligned}
C_{f}=\frac{1}{(1-\phi)^{2.5}}[ & \frac{b_{1}}{b_{2}}\left(\sqrt{b_{4}} \operatorname{erf}\left(\sqrt{a_{1} b_{4} t}\right)+\frac{\exp \left(-a_{1} b_{4} t\right)}{\sqrt{\pi a_{1} t}}\right) \\
& +\left(1-b_{3}\right) \exp \left(a_{0} t\right)\left(\sqrt{b_{5}} \operatorname{erf}\left(\sqrt{a_{1} b_{5} t}\right)+\frac{\exp \left(-a_{1} b_{5} t\right)}{\sqrt{\pi a_{1} t}}\right) \\
& -\frac{b_{1} \exp \left(-b_{2} t\right)}{b_{2}}\left(\sqrt{b_{6}} \operatorname{erf}\left(\sqrt{a_{1} b_{6} t}\right)+\frac{\exp \left(-a_{1} b_{6} t\right)}{\sqrt{\pi a_{1} t}}\right) \\
& +\frac{b_{1} \exp \left(-b_{2} t\right)}{b_{2}}\left(\sqrt{b_{7}} \operatorname{erf}\left(\sqrt{a_{4} b_{7} t}\right)+\frac{\exp \left(-a_{4} b_{7} t\right)}{\sqrt{\pi a_{4} t}}\right) \\
& \left.-\frac{b_{1}}{b_{2}}\left(\sqrt{b_{0}} \operatorname{erf}\left(\sqrt{a_{4} b_{0} t}\right)+\frac{\exp \left(-a_{4} b_{0} t\right)}{\sqrt{\pi a_{4} t}}\right)+b_{3} \frac{\exp \left(-M^{2} a_{3} t\right)}{\sqrt{\pi a_{1} t}}\right] .
\end{aligned}
$$

\subsection{Nusselt number.}

From the temperature field, the non-dimensionless form of the Nusselt number is given as follows:

$$
N u=-\frac{k_{n f}}{k_{f}}\left[\frac{\partial \theta}{\partial \eta}\right]_{\eta=0}=-x_{4}\left[\frac{\partial \theta}{\partial \eta}\right]_{\eta=0} .
$$

From Eqs. (14) and (18), the Nusselt number equation is obtained as below:

$$
N u=x_{4}\left[\sqrt{b_{0}} \operatorname{erf}\left(\sqrt{a_{4} b_{0} t}\right)+\frac{\exp \left(-a_{4} b_{0} t\right)}{\sqrt{\pi a_{4} t}}\right] .
$$

\section{Results and Discussion}

The numerical results of the present physical problem velocity and temperature fields, the rate of heat transfer and skin-friction for $\mathrm{Cu}$-water, $\mathrm{Ag}$-water, and $\mathrm{CuO}$-water nanofluids with various pertinent parameters, i.e., magnetic parameter $\left(M^{2}\right)$, radiation parameter $(N r)$, solid volume fraction $(\phi)$, time $(\tau)$, exponential accelerating parameter $\left(a_{0}\right)$ and heat generation /absorption parameter $(Q)$ are computed and presented in Figures 2-23. The values of the solid volume fraction are taken in the range of $0 \leq \phi \leq 0.05$. The case of $M^{2}=0$ represents the absence of a magnetic field and $\phi=0$ represents the regular fluid (i.e., water).

The influences of time, heat generation/absorption, solid volume fraction, and radiation parameter on temperature profiles are plotted in Figures 2-7. Figure 2 displays the temperature profiles for different nanofluids with the nanoparticle volume fraction $\phi=0.05$ (5 volume \%) and the regular fluid at the time $(\mathrm{Nr}=5)$. The temperature decreases gradually along $\eta$ to a free stream temperature $(\theta=0)$. It can be seen that the temperature of the nanofluid is higher than the regular fluid, which indicates that the heat transfer is greater in the case of nanofluid as compared to the regular fluid (water). Further, the temperature profile is increasing slightly for nanofluids in the order of $\mathrm{CuO}$-water, $\mathrm{Cu}$-water, and $\mathrm{Ag}$-water nanofluid. Ag-water's temperature profile is slightly higher than that of $\mathrm{Cu}$-water and $\mathrm{CuO}$-water because $\mathrm{Ag}$ nanoparticles' thermal conductivity is the highest among $\mathrm{Cu}$ and $\mathrm{CuO}$ nanoparticles. The 
temperature difference between the $\mathrm{Cu}$-water and $\mathrm{CuO}$-water nanofluids is negligibly minimum.

In Figure 3, the transient nature of the temperature profile with respect to time in the case of heat absorption $(Q>0)$ for $\mathrm{Cu}$-water is presented. The temperature profile is increasing with time until it achieves steady-state conditions. This is due to the heat transferred from the plate to the fluid increases with time, raising the fluid temperature. The temperature decreases gradually along $\eta$ until it satisfies the free stream condition. The effect of time on the temperature profile for $\mathrm{Cu}$-water nanofluid in the case of heat generation $(Q<0)$ is shown in Figure 4 . It shows that the temperature profile increases significantly with increasing time. The temperature at higher values of time $(\tau=0.6,1,1.5)$ first increases to a peak value near the plate; then it decreases gradually as $\eta$ increases. On the other hand, the temperature at lower values of time $(\tau=0.2,0.4)$ gradually decreases away from the plate to the free stream temperature. It is further noticed that the peak temperature formed is further away from the plate as time increases.

Figure 5 illustrates the temperature distributions at different values of heat generation/absorption parameters for $\mathrm{Cu}$-water nanofluid. For the increasing value of the heat absorption parameter, the temperature profile reduces, but an opposite trend is observed with increasing heat generation. It is noticed that the temperature decreases gradually away from the plate in the case of heat absorption, but a different trend is seen for the higher value of heat generation parameter where a peak temperature is formed near the plate before it decreases gradually to the free stream temperature. Also, in the case of heat generation, the temperature profiles are increasing considerably due to the nanofluid's higher thermal conductivity.

The effect of solid volume fraction on the temperature distribution for $\mathrm{Cu}$-water nanofluid is plotted in Figure 6. It shows that the temperature decreases exponentially along $\eta$ until it achieves the free stream temperature. The increasing value of solid volume fraction augments the temperature profile due to the improved thermal conductivity with the addition of nanoparticles. In Figure 7, the temperature profiles at various radiation parameter values are demonstrated. The temperature profile increases with increasing radiation effect because the increasing radiation induces higher heat flux, and hence, the boundary layer's temperature increases. The temperature decreases monotonically until it reaches the free stream temperature. However, the variation of temperature profiles is more significant at lower values of radiation parameters.

Figures 8-14 depict the influence of various parameters on the fluid velocity in the boundary layer, and it should be noted that these figures involve two different cases, i.e., the magnetic force fixed relative to the fluid $(K=0)$ and to the plate $(K=1)$. Figure 8 shows the velocity distributions for different types of nanofluids. The two magnetic force cases provide a similar trend, where both cases have the same velocity at the surface of the plate, and the velocity reduces as $\eta$ increases. The freestream velocity for $K=0$ is zero, whereas the free stream velocity for $K=1$ varies with nanoparticles. For $K=0$, the velocity profile increases in the order of the nanofluids $\mathrm{Ag}$-water, $\mathrm{Cu}$-water, and $\mathrm{CuO}$-water. The velocity profiles of $\mathrm{Ag}$ water and $\mathrm{Cu}$-water nearly coincide, but the velocity profile of $\mathrm{CuO}$-water differs prominently from $\mathrm{Ag}$-water and $\mathrm{Cu}$-water. On the other hand, for $K=1$, the velocity profile increases in the order of $\mathrm{CuO}$-water, $\mathrm{Ag}$-water, and $\mathrm{Cu}$-water. It is highlighted that, among the nanofluids, $\mathrm{CuO}$-water nanofluid has the highest velocity profile in the case of $K=0$ and lowest in the 
case of $K=1$. The influence of dimensionless time on the velocity field for $\mathrm{Cu}$-water nanofluid is plotted in Figure 9. The fluid velocity at the plate's surface differs with time; however, two different magnetic force cases have the same velocity at the surface of the plate accordingly. Besides, as time progresses, the velocity profile increases for both cases. This is due to the accumulation of buoyancy force as time increases, leading to the rise of fluid velocity. The velocity gradually decreases from the plate for both cases until it achieves free stream velocity or steady-state velocity. The freestream velocity for $K=0$ is zero, whereas the free stream velocity is a non-zero steady-state velocity that differs over time.

In Figure 10, the velocity profile for $\mathrm{Cu}$-water nanofluid with various solid volume fractions is depicted. The velocity profile reduces as the solid volume fraction increases owing to the increment of fluid viscosity by adding nanoparticles. Hence the fluid velocity is reduced. This figure also shows that the velocity decreases gradually as $\eta$ increases. In both cases, the pure fluid has a higher velocity profile than the nanofluid, and the velocity profiles for $K=1$ are higher than $K=0$.

Figure 11 discusses the velocity distributions at different accelerating parameter values. Different accelerating parameter values lead to the different fluid velocities at the plate's surface in both cases of magnetic force. For the case $K=0$, the velocity reduces to a free stream velocity $(U=0)$ away from the plate, while for the case $K=1$, the velocity reduces to different steady-state free stream velocities according to the accelerating parameter. Simultaneously, the increment of accelerating parameter causes the rise in velocity profile, and the velocity profiles for $K=1$ are higher than the case of $K=0$. The distribution of velocity for different values of the magnetic parameter is illustrated in Figure 12. In general, a drastic decrease in fluid velocity is seen in the case of $K=0$ whilst the velocity decreases gradually in the case of $K=1$. The freestream velocity varies with the magnetic parameter in the case of $K=1$ while the free stream velocity is zero in the case of $K=0$. The velocity profile reduces with an increasing magnetic parameter when the magnetic lines of force are fixed relative to the fluid $(K=0)$ because a drag force, called the Lorentz force, is induced by the applied magnetic field, and it tends to oppose the fluid flow. But the velocity profile increases with an increasing magnetic parameter when the magnetic lines of force are fixed relative to the plate $(K=1)$. For both cases, the magnetic field influence on the velocity profile reduces as the magnetic parameter increases.

The velocity distributions for $\mathrm{Cu}$-water nanofluid at various heat generation/absorption parameter values are shown in Figure 13. The increment of heat absorption leads to the decrease of the velocity profile, while the rise of heat generation causes the enhancement of fluid velocity in the boundary layer. The heat generation supplements the fluid's thermal state, leading to the increase in thermal buoyancy force, and thus the fluid velocity increases. Simultaneously, the velocity reduces gradually to free stream velocity in both cases of magnetic force. However, the free stream velocity for $K=1$ reaching a non-zero steady-state value for all $Q$ values and a more prominent variation in the velocity profile can be seen with increasing heat generation.

Figure 14 illustrates the velocity distributions of $\mathrm{Cu}$-water nanofluid at various values of radiation parameters. The increasing value of the radiation parameter causes the rise in velocity profile. The velocity decreases gradually along $\eta$ to attain a free stream velocity for both cases of magnetic force. The velocity profiles reach a non-zero steady-state free stream velocity far away from the plate. From Figures 8 to 14, it is clear that the free stream's velocity 
profiles are remarkably higher in the case of $K=1$ than the case of $K=0$ with respect to all parameters involved.

The Nusselt number variation for different nanofluids with $\phi=0.05$ and regular fluid $(\phi=0)$ is presented in Figure 15 in the presence of radiation and heat absorption. The Nusselt number decreases drastically at small-time values. Then it slowly reduces to a constant value as time progresses. The Nusselt number is less for regular fluid as compared to the nanofluids. Thus the rate of heat transfer is higher for nanofluids than the regular fluid (water). Further, the Nusselt number for $\mathrm{Cu}$-water is the highest, followed by $\mathrm{Ag}$-water and, lastly, $\mathrm{CuO}$-water. However, the Nusselt number variations between $\mathrm{Cu}$-water, $\mathrm{Ag}$-water, and $\mathrm{CuO}$-water nanofluids are very minimum. Figure 16 describes the impact of solid volume fraction on the Nusselt number. The Nusselt number reduces at small values of time as expected, and then it decreases gradually to a constant value as time increases. Concurrently, the increasing solid volume fraction causes the Nusselt number's increment due to increased thermal conductivity by suspending more nanoparticles in the fluid. A similar result was also observed by Turkyilmazoglu and Pop [20] when the solid volume fraction is increased in the presence of radiation effect.

The Nusselt number for various values of heat generation/absorption parameter is illustrated in Figure 17. The increment of heat generation reduces the Nusselt number, while an inverse effect is found with increasing heat absorption. This figure also shows that the heat transfer rate decreases with time. The time taken for the heat transfer rate to reach a steadystate value is shorter in the case of heat absorption compared to the case of heat generation. The negative value of the Nusselt number in the case of heat generation $(Q=-1)$ indicates that the heat transfer is taking place in the opposite direction, i.e., from the nanofluid to the plate at higher values of the time. Figure 18 shows the Nusselt number variation at different radiation parameters for $\mathrm{Cu}$-water nanofluid. The Nusselt number reduces to a constant value as time progresses and the augmentation of the radiation parameter causes a reduction in the Nusselt number. It is further revealed that a protrusive variation of the Nusselt number is observed at lower radiation parameter values at an early time.

The skin-friction variation for different nanofluids is plotted in Fig. 19. In both magnetic force cases, the skin-friction first declines drastically to a minimum value at small values of time; after that, a sudden increase is seen as time progresses. The reason is that the plate velocity is lower than the fluid velocity at a small-time, resulting from a decrease in the skin-friction. As time progresses, the plate velocity dominates the fluid velocity that causes a drag on the plate surface. Thereby skin-friction increases rapidly with time. Ag-water nanofluid causes the highest skin-friction, whereas the lowest skin-friction is caused by $\mathrm{CuO}$-water nanofluid. The skin-friction for $\mathrm{Cu}$-water and $\mathrm{Ag}$-water nearly coincide for $K=0$, while the skin-friction for $\mathrm{Cu}$-water and $\mathrm{CuO}$-water coincide with each other for $K=1$. Also, the skin friction for nanofluids is greater in the case of $K=0$ than $K=1$. Fig. 20 illustrates the skinfriction variation at different values of solid volume fraction for $\mathrm{Cu}$-water nanofluid. It is observed that the increasing value of solid volume fraction leads to the rise of skin-friction for both cases of magnetic force. The skin-frictions for both cases first decrease substantially at small values of time, then a drastic rise is observed in the case of $K=0$ while the skin-friction for $K=1$ increases gradually with time as compared to the case of $K=0$. It is seen that the skin-friction for pure fluid is smaller than nanofluids in both cases of magnetic force, and the skin-friction is greater in the case of $K=0$. 
Figure 21 shows the skin-friction variation with different accelerating parameters for $\mathrm{Cu}$-water nanofluid. The rise of the accelerating parameter leads to the increase of skin-friction for both cases of magnetic force. However, the skin-friction at a high value of accelerating parameter first decreases slightly to a minimum value, then a gradual increase is observed with increasing time. Meanwhile, the skin-friction at a low value of accelerating parameter reduces gradually until it becomes constant as time progresses.

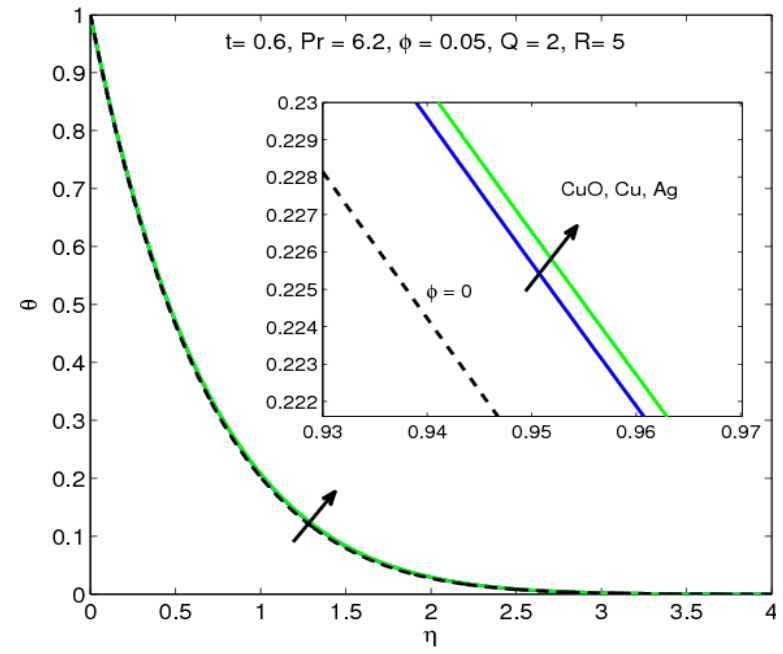

Figure 2. Temperature profiles for different nanofluids

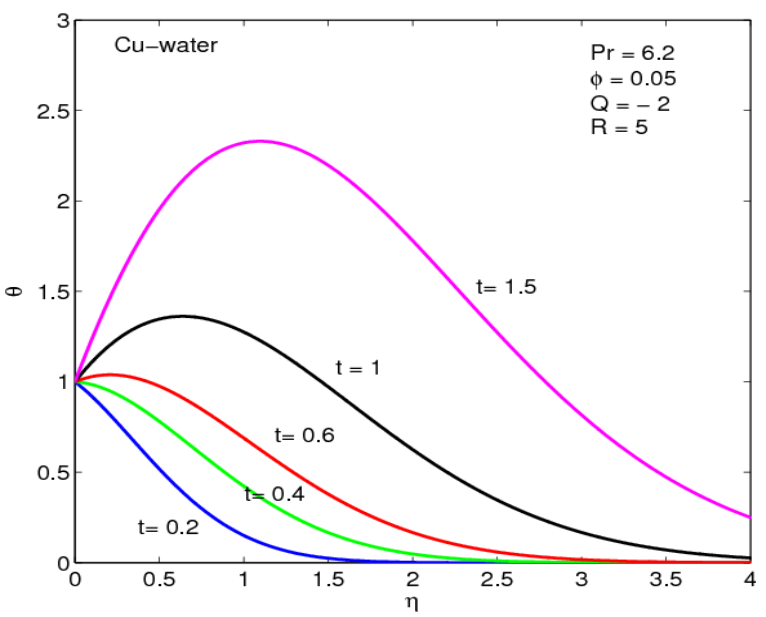

Figure 4. Temperature distributions at different $t$ in

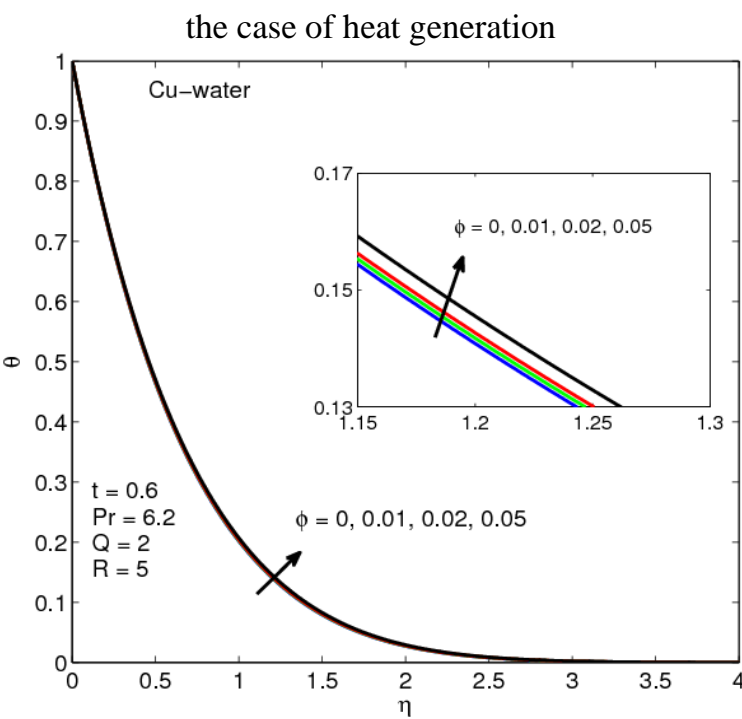

Figure 6. Temperature profiles at different values of $\phi$

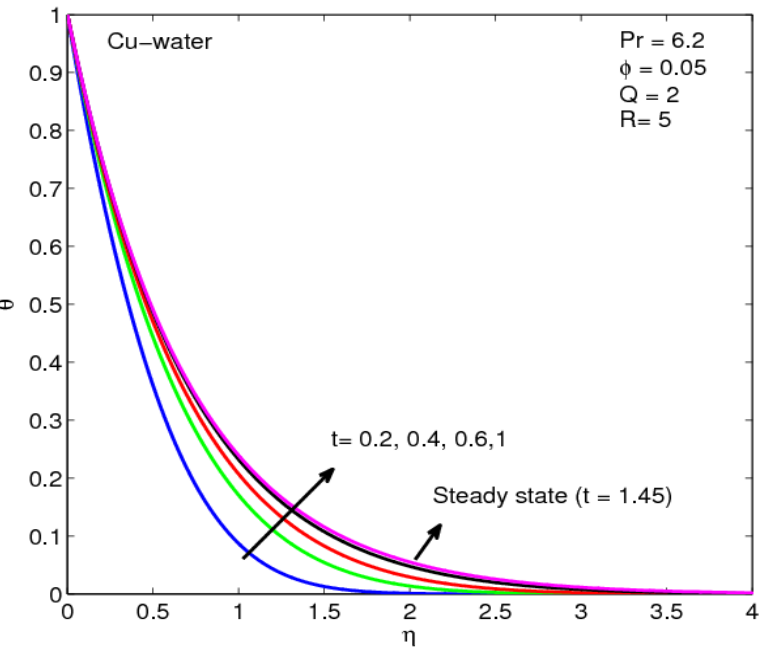

Figure 3. Temperature profiles at different $t$ in the

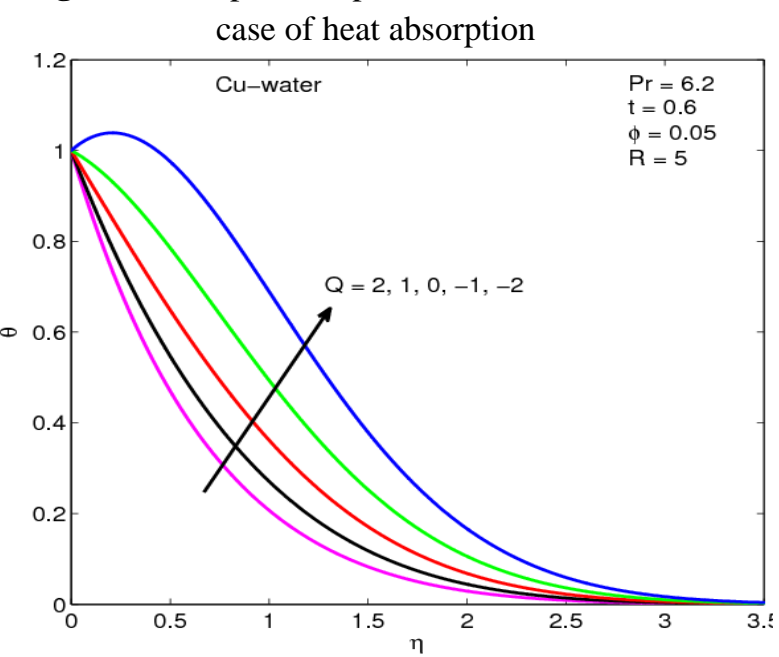

Figure 5. Temperature profiles at different values $Q$

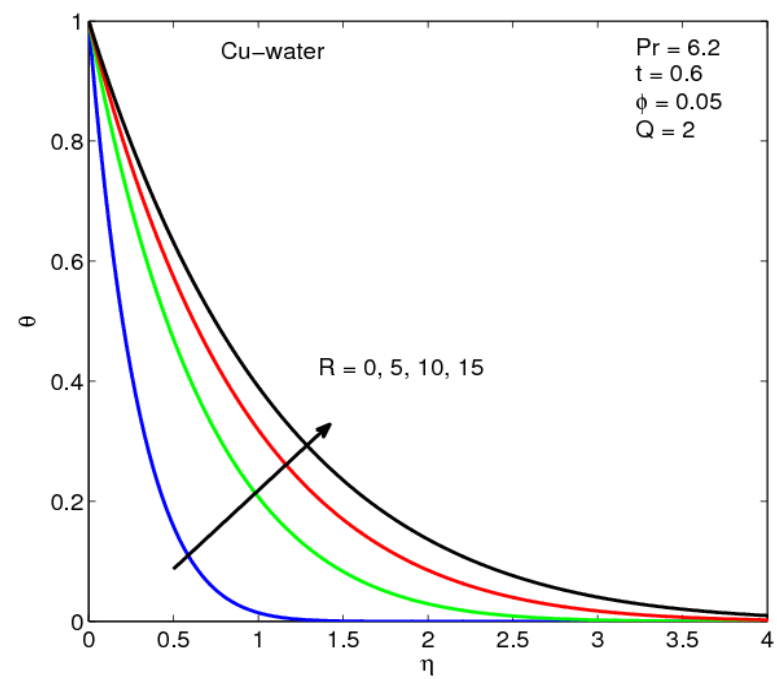

Figure 7. Temperature profiles at different values of $R$ 


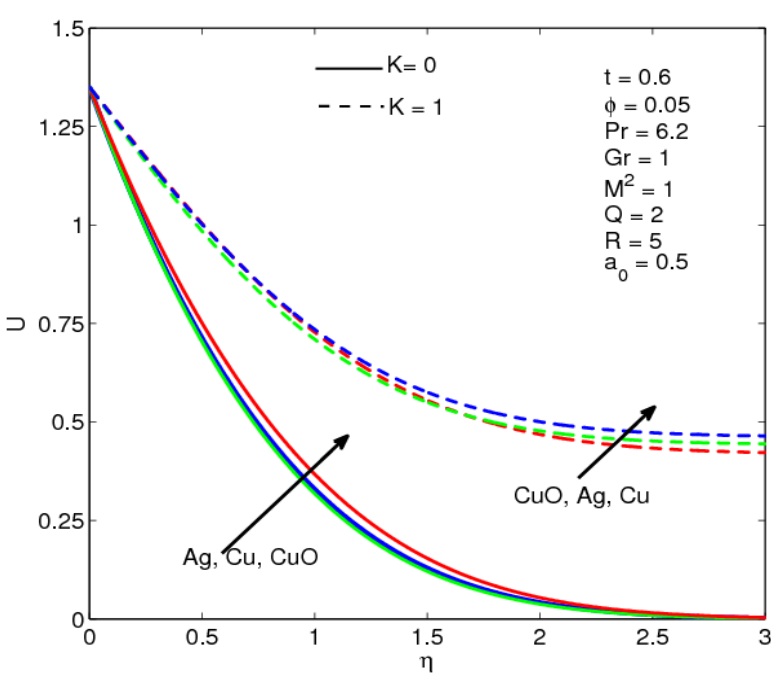

Figure 8. Velocity profiles for different nanofluids

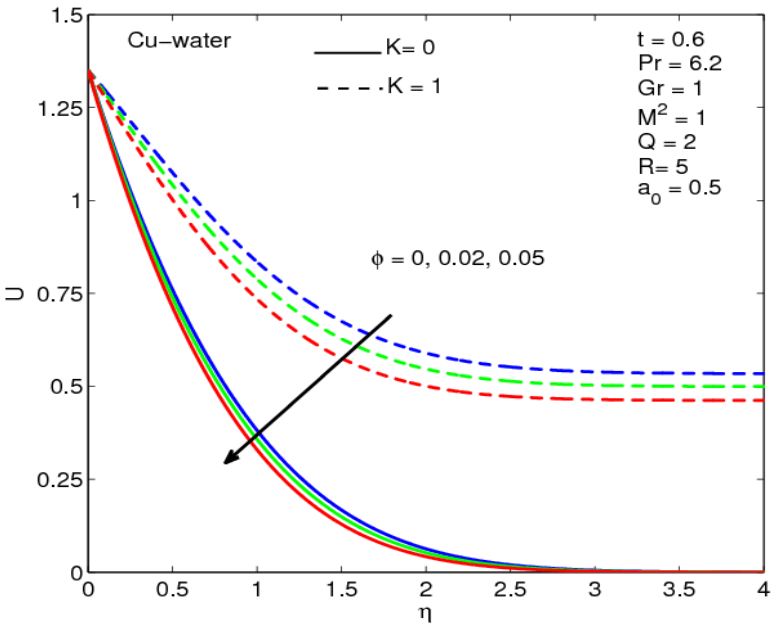

Figure 10. Velocity distributions at different $\phi$

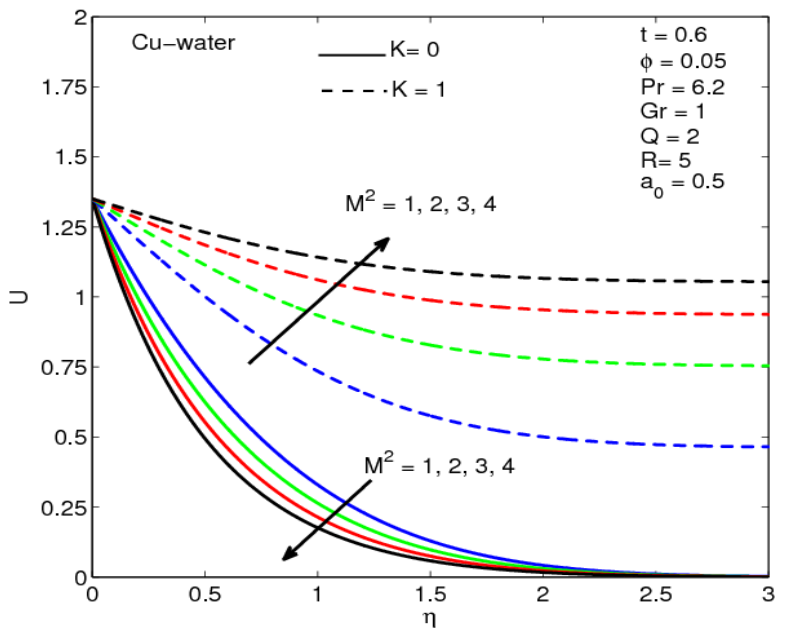

Figure 12. Velocity profiles at different values of $M^{2}$

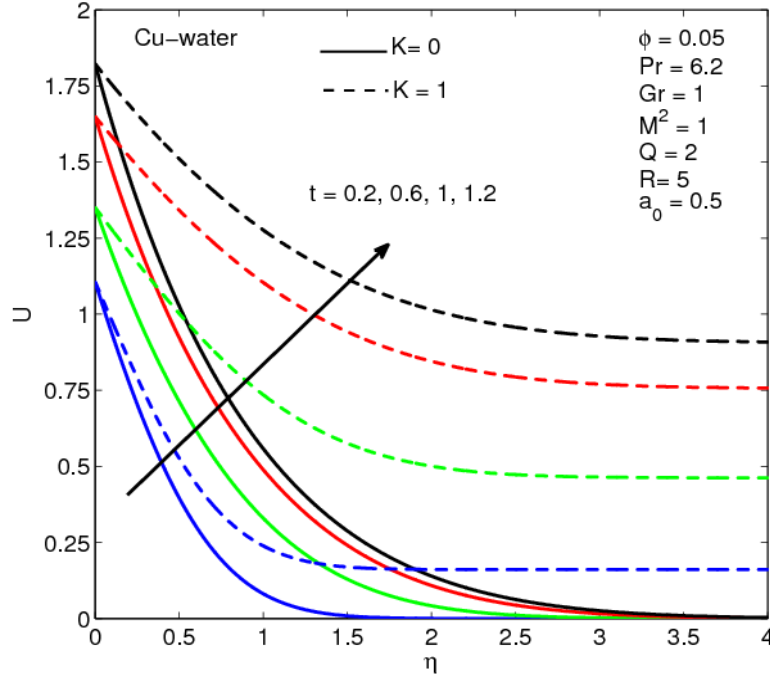

Figure 9. Velocity distributions at different $t$

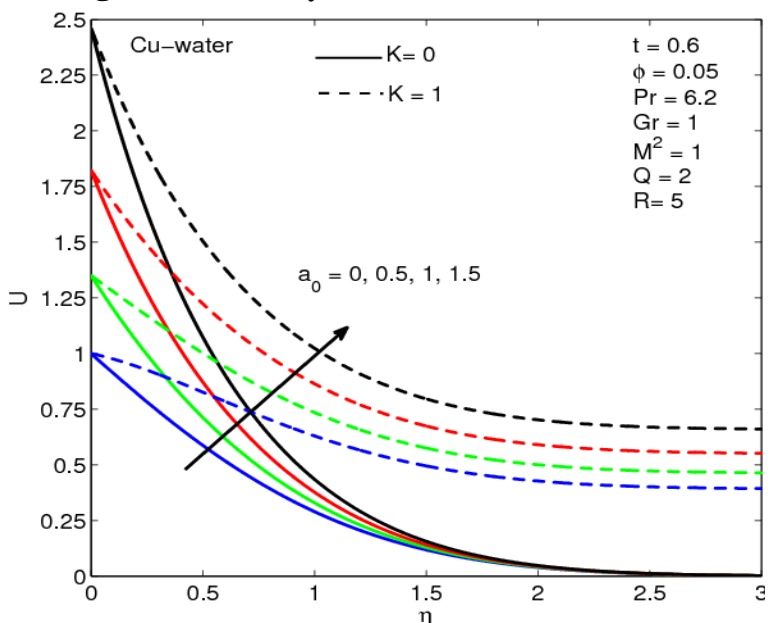

Figure 11. Velocity profiles at different values of $a_{0}$

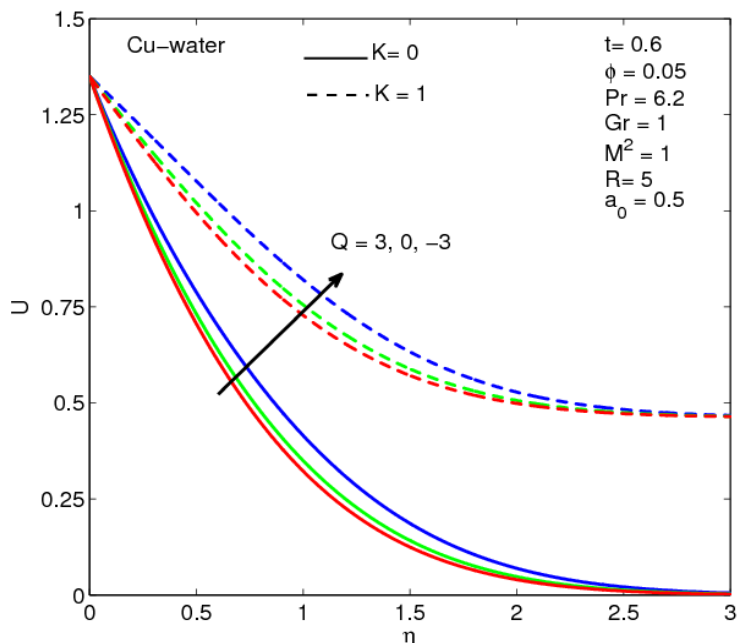

Figure 13. Velocity profiles at different values of $Q$ 


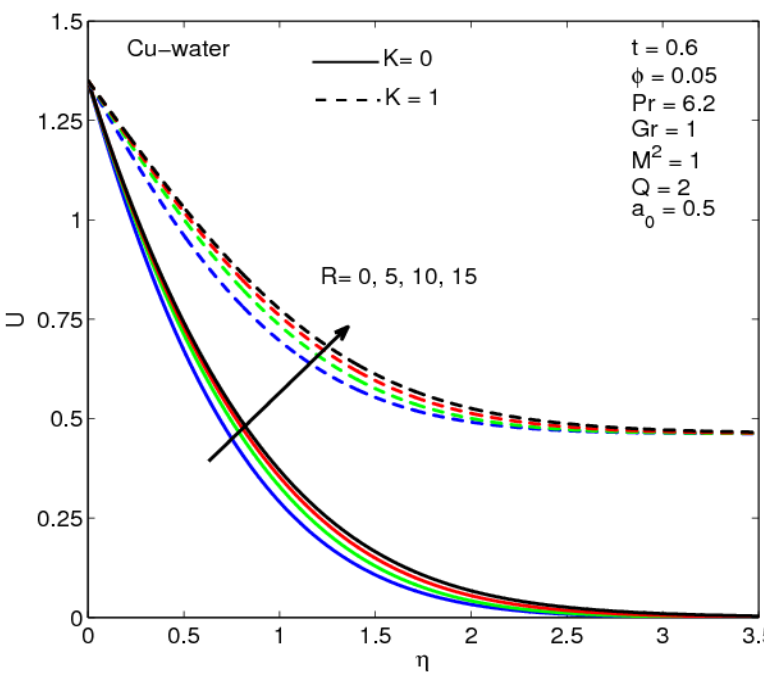

Figure 14. Velocity profiles at different values of $R$

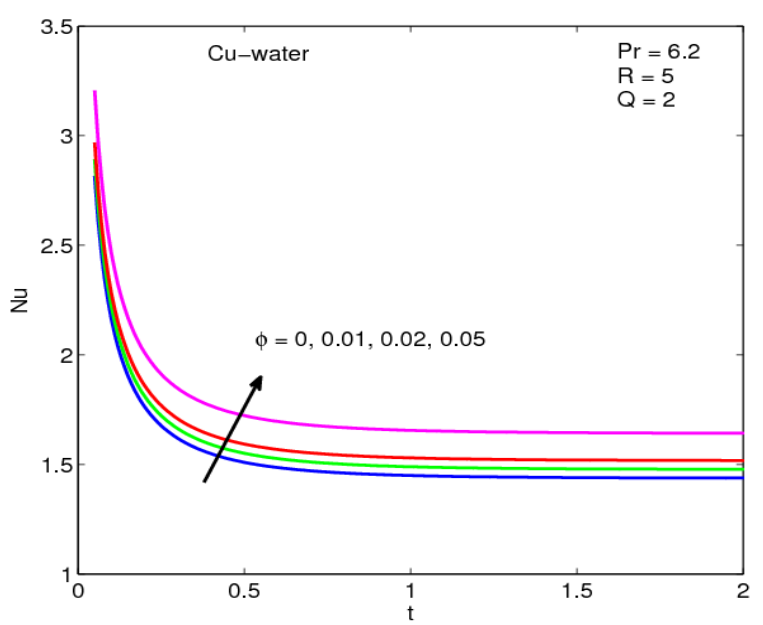

Figure 16. Nusselt number variation at different $\phi$

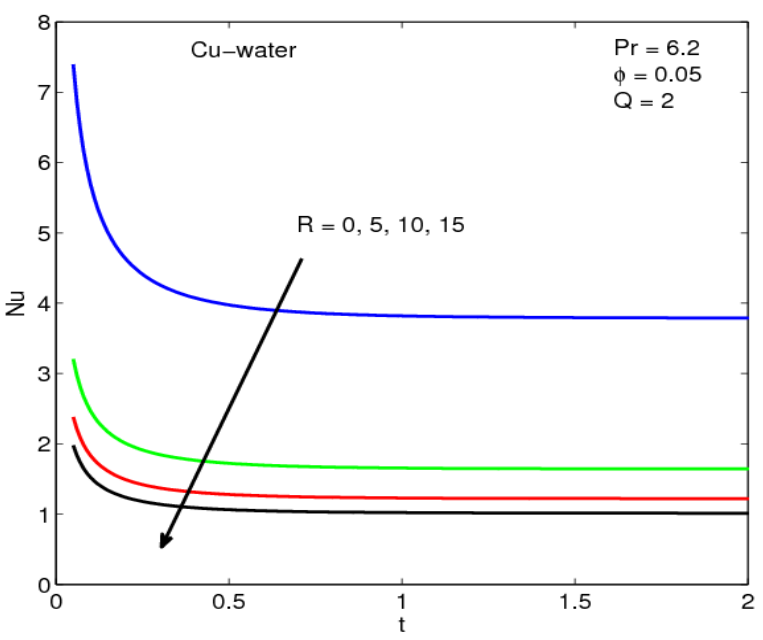

Figure 18. Nusselt number variation at different values of $R$

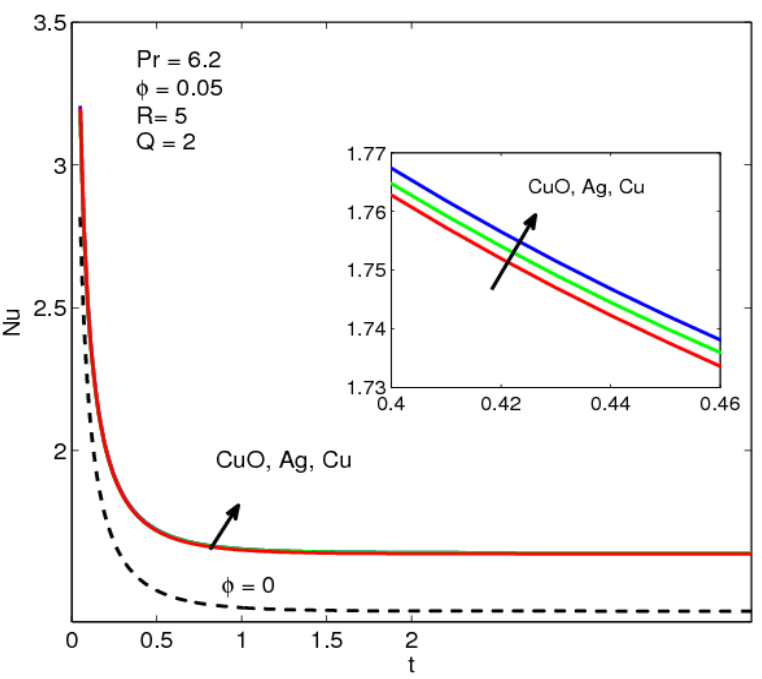

Figure 15. Nusselt number variation for different nanofluids

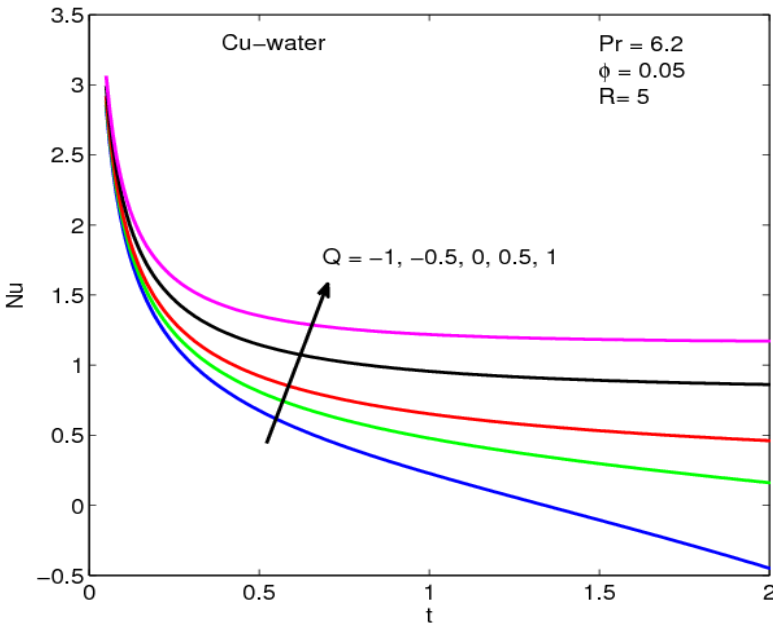

Figure 17. Nusselt number variation at different values of $Q$

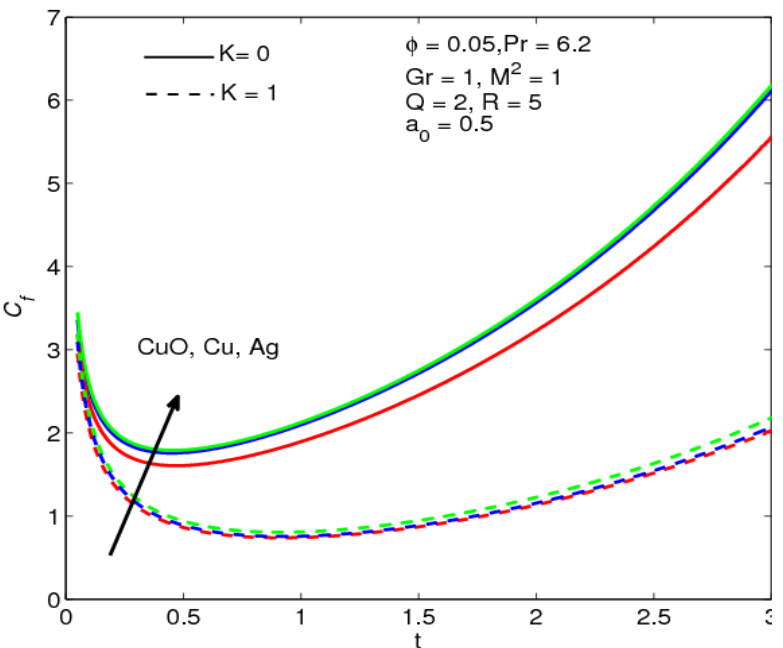

Figure 19. Skin-friction variation for different nanofluids 


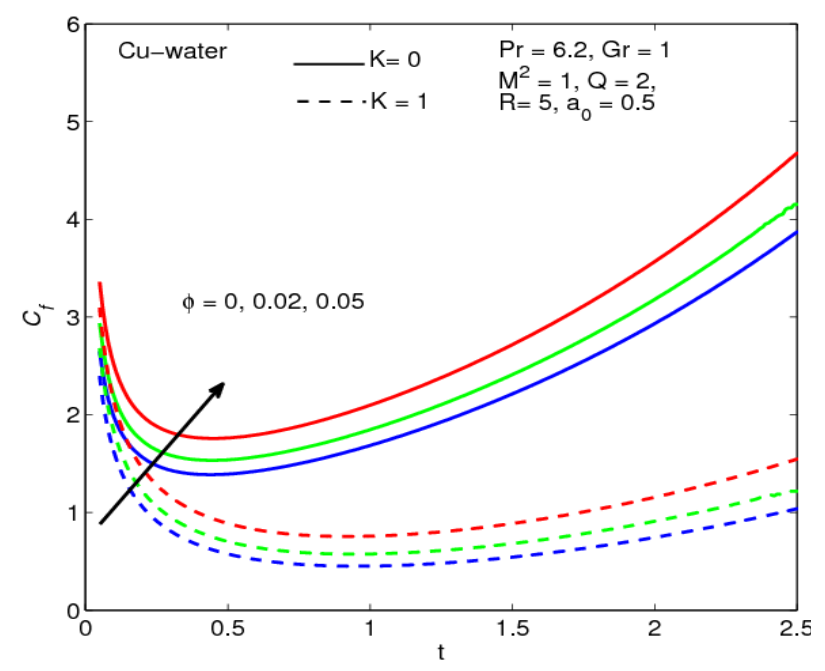

Figure 20. Skin-friction variation at different values of $\phi$

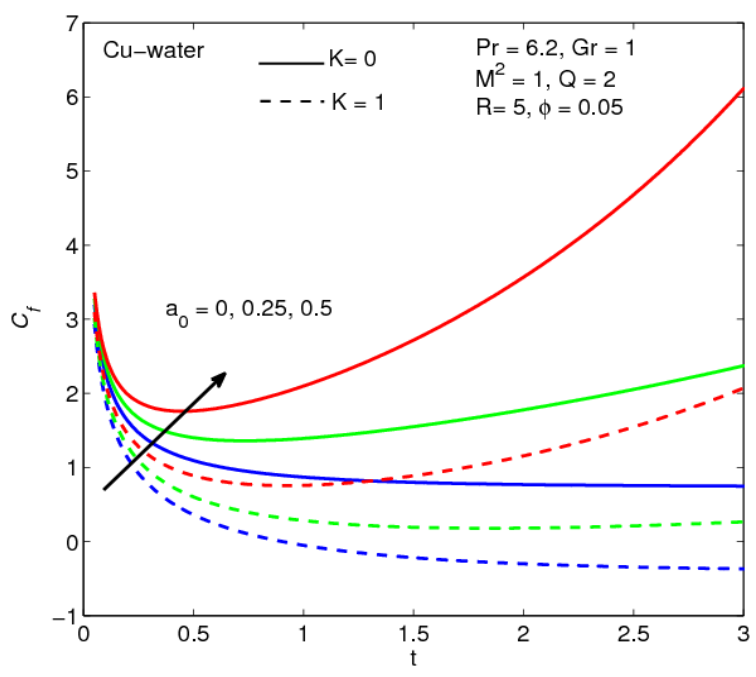

Figure 21. Skin-friction variation at different values of $a_{0}$

The impact of the magnetic parameter on the skin-friction variation is depicted in Figure 22 for $\mathrm{Cu}$-water nanofluid. In the case of $K=0$, the increment of magnetic parameter enhances the skin-friction, but an opposite trend is observed for $K=1$. The skin-frictions for both cases decrease marginally to a minimum value at small-time values; after that, the skin-friction increases gradually as time increases. The skin-friction for $K=0$ is greater than $K=1$. It also shows that a more significant variation of skin-friction is recorded at a higher value of time.

\section{Conclusions}

The natural convective heat transfer and nanofluid flow past an exponentially accelerating vertical plate with the magnetic field fixed relative to the fluid or the plate have been discussed. Laplace transform method has been applied to solve the dimensionless governing equations. The effects of time, solid volume fraction, heat generation/absorption, radiation, magnetic and accelerating parameters on the heat and fluid flow characteristics are discussed graphically. The main conclusions are summarized as follows: The velocity profile reduces with increasing solid volume fraction and heat absorption, but an opposite trend is observed with the increment of time, accelerating parameter, heat generation, and radiation parameter; The velocity profile increases as the magnetic parameter increase when the magnetic force fixed relative to the plate, while the reverse trend is observed when the magnetic force fixed relative to the fluid; The velocity profiles for different pertinent parameters are higher when the magnetic force is fixed relative to the plate than to the fluid; The Nusselt number reduces with increasing radiation parameter and heat generation, but it increases when solid volume fraction and heat absorption increase.

\section{Funding}

This research received no external funding.

\section{Acknowledgments}

The authors would like to thank the anonymous reviewers for their valuable comments and suggestions to improve the paper's quality. 


\section{Conflicts of Interest}

\section{The authors declare no conflict of interest.}

\section{References}

1. Choi, S.U.; Eastman, J.A. Enhancing thermal conductivity of fluids with nanoparticles; Argonne National Lab., IL (United States): 1995.

2. Eastman, J.A.; Choi, U.S.; Li, S.; Thompson, L.J.; Lee, S. Enhanced Thermal Conductivity through the Development of Nanofluids. MRS Proceedings 1996, 457, 3, https://doi.org/10.1557/PROC-457-3.

3. Choi, S.U.S.; Zhang, Z.G.; Yu, W.; Lockwood, F.E.; Grulke, E.A. Anomalous thermal conductivity enhancement in nanotube suspensions. Appl. Phys. Lett. 2001, 79, 2252-2254, https://doi.org/10.1063/1.1408272.

4. Akmal, N.; Sagheer, M.; Hussain, S.; Kamran, A. Investigation of free convection in micropolar nanofluid with induced magnetic field. The European Physical Journal Plus 2019, 134, 235, https://doi.org/10.1140/epjp/i2019-12512-7.

5. Kumar, T.S.; Kumar, B.R.; Makinde, O.D.; Vijaya Kumar, A.G. Magneto-Convective Heat Transfer in Micropolar Nanofluid over a Stretching Sheet with Non-Uniform Heat Source/Sink. Defect and Diffusion Forum 2018, 387, 78-90, https://doi.org/10.4028/www.scientific.net/ddf.387.78.

6. Das, S.K.; Choi, S.U.S. A Review of Heat Transfer in Nanofluids. In Advances in Heat Transfer, Irvine, T.F., Hartnett, J.P., Eds. Elsevier: 2009; 41, 81-197, https://doi.org/10.1016/s0065-2717(08)41002-x.

7. Sravan kumar, T. Impact of Lorentz force on free convection flow of a viscous fluid past an infinite vertical plate. SN Applied Sciences 2019, 1, 1257, https://doi.org/10.1007/s42452-019-1292-8.

8. Sravan Kumar, T.; Dinesh, P.A.; Makinde, O.D. Impact of Lorentz Force and Viscous Dissipation on Unsteady Nanofluid Convection Flow over an Exponentially Moving Vertical Plate. Mathematical Models and Computer Simulations 2020, 12, 631-646, https://doi.org/10.1134/s2070048220040110.

9. Shah, Z.; Alzahrani, E.O.; Dawar, A.; Ullah, A.; Khan, I. Influence of Cattaneo-Christov model on DarcyForchheimer flow of Micropolar Ferrofluid over a stretching/shrinking sheet. International Communications in Heat and Mass Transfer 2020, 110, 104385, https://doi.org/10.1016/j.icheatmasstransfer.2019.104385.

10. Tiwari, A.; Shah, P.D.; Chauhan, S.S. Analytical study of micropolar fluid flow through porous layered microvessels with heat transfer approach. The European Physical Journal Plus 2020, 135, 209, https://doi.org/10.1140/epjp/s13360-020-00128-x.

11. Mahdy, A.; ElShehabey, H.M. Uncertainties in physical property effects on viscous flow and heat transfer over a nonlinearly stretching sheet with nanofluids. International Communications in Heat and Mass Transfer 2012, 39, 713-719, https://doi.org/10.1016/j.icheatmasstransfer.2012.03.019.

12. Mahdy, A. Unsteady mixed convection boundary layer flow and heat transfer of nanofluids due to stretching sheet. Nucl. Eng. Des. 2012, 249, 248-255, https://doi.org/10.1016/j.nucengdes.2012.03.025.

13. Vemula, R.; Chamkha, A.J.; Mallesh, M.P. Nanofluid flow past an impulsively started vertical plate with variable surface temperature. International Journal of Numerical Methods for Heat \& Fluid Flow 2016, 26, 328-347, https://doi.org/10.1108/hff-07-2014-0209.

14. Kumaresan, E.; Sravan Kumar, T.; Suresh Babu, R. MHD slip flow and heat transfer of Cu-Fe3O4/ ethylene glycol-based hybrid nanofluid over a stretching surface. Biointerface Research in Applied Chemistry 2020, 11, 11956-11968, https://doi.org/10.33263/briac114.1195611968.

15. Cao, Z.; Zhao, J.; Wang, Z.; Liu, F.; Zheng, L. MHD flow and heat transfer of fractional Maxwell viscoelastic nanofluid over a moving plate. J. Mol. Liq. 2016, 222, 1121-1127, https://doi.org/10.1016/j.molliq.2016.08.012.

16. Mahanthesh, B.; Gireesha, B.J.; Gorla, R.S.R.; Abbasi, F.M.; Shehzad, S.A. Numerical solutions for magnetohydrodynamic flow of nanofluid over a bidirectional non-linear stretching surface with prescribed surface heat flux boundary. J. Magn. Magn. Mater. 2016, 417, 189-196, https://doi.org/10.1016/j.jmmm.2016.05.051.

17. Hamad, M.A.A.; Pop, I.; Md Ismail, A.I. Magnetic field effects on free convection flow of a nanofluid past a vertical semi-infinite flat plate. Non-linear Analysis: Real World Applications 2011, 12, 1338-1346, https://doi.org/10.1016/j.nonrwa.2010.09.014. 
18. Khan, W.A.; Rashad, A.M.; El-Kabeir, S.M.M.; El-Hakiem, A.M.A. Framing the MHD MicropolarNanofluid Flow in Natural Convection Heat Transfer over a Radiative Truncated Cone. Processes 2020, 8 , https://doi.org/10.3390/pr8040379.

19. Ibrahim, W.; Gadisa, G. Non-linear convective boundary layer flow of micropolar-couple stress nanofluids past permeable stretching sheet using Cattaneo-Christov heat and mass flux model. Heat Transfer 2020, 49, 2521-2550, https://doi.org/10.1002/htj.21733.

20. Turkyilmazoglu, M.; Pop, I. Heat and mass transfer of unsteady natural convection flow of some nanofluids past a vertical infinite flat plate with radiation effect. Int. J. Heat Mass Transfer 2013, 59, 167-171, https://doi.org/10.1016/j.ijheatmasstransfer.2012.12.009.

21. Turkyilmazoglu, M. Unsteady Convection Flow of Some Nanofluids Past a Moving Vertical Flat Plate With Heat Transfer. J. Heat Transfer 2013, 136, https://doi.org/10.1115/1.4025730.

22. Sheikholeslami, M.; Bandpy, M.G.; Ellahi, R.; Zeeshan, A. Simulation of MHD CuO-water nanofluid flow and convective heat transfer considering Lorentz forces. J. Magn. Magn. Mater. 2014, 369, 69-80, https://doi.org/10.1016/j.jmmm.2014.06.017.

23. Ahmed M, B.; Hanan, E.; Osama, O.; Kholmirzo, T. K.; Tarek, H.; Medhat, A. I. Effect of nano metal oxides on heme molecule: molecular and biomolecular approaches. Biointerface Research in Applied Chemistry 2019, 10, 4837-4845, https://doi.org/10.33263/briac101.837845.

24. Khan, M.N.; Nadeem, S.; Muhammad, N. Micropolar fluid flow with temperature-dependent transport properties. Heat Transfer 2020, 49, 2375-2389, https://doi.org/10.1002/htj.21726.

25. Pedram, E.; Ehsan, K. Experimental investigation of rheological properties and formation damage of waterbased drilling fluids in the presence of $\mathrm{Al} 2 \mathrm{O} 3$, Fe3O4, and $\mathrm{TiO} 2$ nanoparticles. Biointerface Research in Applied Chemistry 2020, 10, 5886-5894, https://doi.org/10.33263/briac104.886894.

26. Sabri, N.; Moulai-Mostefa, N. Formulation and Characterization of Oil-in-Water Emulsions Stabilized by Saponins Extracted from Hedera Helix Algeriensis Using Response Surface Method. Biointerface Research in Applied Chemistry 2020, 10, 6282- 6292, https://doi.org/10.33263/briac105.62826292.

27. Ali, F.; Gohar, M.; Khan, I. MHD flow of water-based Brinkman type nanofluid over a vertical plate embedded in a porous medium with variable surface velocity, temperature and concentration. J. Mol. Liq. 2016, 223, 412-419, https://doi.org/10.1016/j.molliq.2016.08.068.

28. Kataria, H.R.; Mittal, A.S. Velocity, mass and temperature analysis of gravity-driven convection nanofluid flow past an oscillating vertical plate in the presence of magnetic field in a porous medium. Appl. Therm. Eng. 2017, 110, 864-874, https://doi.org/10.1016/j.applthermaleng.2016.08.129.

29. Moreau, R.J. Magnetohydrodynamics; Springer Science \& Business Media: 1990; Vol. 3.

30. Cramer, K.R.; Pai, S.I. Magnetofluid dynamics for engineers and applied physicists; McGraw-Hill Book Company: United States, 1973.

31. Raptis, A.; Singh, A.K. MHD free convection flow past an accelerated vertical plate. International Communications in Heat and Mass Transfer 1983, 10, 313-321, https://doi.org/10.1016/07351933(83)90016-7.

32. Tokis, J.N. A class of exact solutions of the unsteady magnetohydrodynamic free-convection flows. Astrophysics and Space Science 1985, 112, 413-422, https://doi.org/10.1007/bf00653524.

33. Rosseland, S. Springer-Verlag; Berlin: 1931. Astrophysik und atom-theoretische Grundlagen.

34. Singh, S.; Dhal, K.; Talukdar, M. A Comparative study on the effect of temperature and concentration on density, sound velocity and their derived properties for diclofenac potassium in aqueous Urea media. Biointerface Res. Appl. Chem 2020, 10, 6377-6388, https://doi.org/10.33263/briac105.63776388. 